\title{
EFFECTS OF COMPUTER-ASSISTED INSTRUCTION ON SECONDARY SCHOOL STUDENTS' ACADEMIC ACHIEVEMENT IN THE LEARNING OF GOVERNMENT AS A SUBJECT
}

\author{
ODE, Dickson (Ph.D) \\ Wesley High School, P. O. Box 1100, Otukpo, Benue State, Nigeria.
}

\begin{abstract}
This study investigated the effects computer-assisted instruction in collaboration with conventional instruction method would have on secondary school students' academic achievement in government as a subject. One null hypothesis was formulated and tested at 0.05 level of significance. The instrument for data collection was a-25 item teacher made Government Achievement Test which was validated and reliability index of 0.86 established. The post-test only experimental design was adopted. A purposive sample of 100 senior secondary students which was divided into two groups-the experimental group and control group with each group consisting of 50 students was investigated.

Each of the two groups was taught government for eight weeks using CAI programmed packages for the experimental group and conventional instruction method for the control group. At the end of the eighth week, post-test was administered on the students to determine difference in academic achievement if any, between the two groups. Using means and t-test in analyzing the data, the result showed that, students taught government using computer-assisted instruction significantly performed better than students taught government using conventional instruction method. The study recommended among others that, government should not hesitate to fully introduce and implement computer-assisted instruction in Nigerian secondary schools to enhance quality learning and teaching of government as a subject and all other subjects.
\end{abstract}

\section{KEYWORDS}

Computer-assisted instruction, secondary school students, academic achievement, government.

\section{INTRODUCTION}

The falling standard of education in Nigeria is no longer news. Agreeing with this, Uwameiye (2014) asserted that, a trip down the lane of education indicated that, education in Nigeria has been declining in purpose. Earlier, Duze (2011) in his survey of opinion of 5507 stakeholders to determine whether educational standards were actually falling in Nigeria and at what level it was most grievous, found that, standards had fallen at all levels of education with the tertiary level being most hit, followed by secondary level and at the least end, primary level. The above 
International Journal of Education (IJE) Vol.6, No.1/2, June 2018

scenario calls for appropriate methods to be sought and applied to stem the tide. This is in consonance with the view of Olugbenga (2016) where he stated that, the education sector was heading towards a total collapse and everything within our capacity must be done to make sure that doesn't happen. Olugbenga lamented the persistent failure of candidates in WAEC/JAMB and other examinations with unemployable graduates that our universities produce every year, and saw this as a threat to the future of the country. As part of solution to this phenomenon, Olugbenga suggested that, government and individuals must not delay in providing the necessary infrastructure by bringing in the use of internet, technological and digital tools into the sector so as to drive the needed sustainable change. Olugbenga continued that, massive training on the use of internet, technological and digital tools should be organized for teachers so as to empower them to meet up with the $21^{\text {st }}$ century education. These suggestions imply that, computer- assisted instruction (CAI) which is digital in nature and constitutes one of the modes of instructional technology is a necessity for the enhancement of students' academic performance and quality teaching in our educational system today.

Rendering their perceptions on what computer-assisted instruction implies and the attendant advantage in the educational system, Rogers, Boettcher, Howard, Justice and Schenk (1995) stated that, computer-assisted instruction (CAI) is an interactive instructional technique whereby a computer is used to present instructional material and monitor learning that takes place. According to Rogers, Berg, Boettcher, Howard, Justice and Schenky, CAI uses a combination of texts, graphs, sound and video in enhancing the learning process. These authorities (Rogers, Berg, Boettcher, Howard, Justice and Schenky) uncovered that, CAI helps students learn new materials through interaction with the computer and students can progress in learning with their own speed. Adding to the importance of computer-assisted instruction, WikiEducator (2008) stated that, it (computer-assisted instruction) helps the learner to understand difficult concepts through multisensory approach. WikiEducator also stated that, CAI helps the learner learn more and more rapidly.

Additionally, WikiEducator stated that, CAI helps the teacher devote more time to individual students. Again, unfolding the meaning of computer-assisted instruction and its relevance, Jones (2017) referred to computer-assisted instruction as educational system of instruction performed almost entirely by the computer. According Jones, CAI allows students to work at their own pace along with direct and individualized feedback. Jones also unfolded that, with CAI, misconceptions can be corrected as they appear and the students' records and scores are made available to the teacher.

Furthermore, in the views of Benton, Chisholm, Tytler, Bell, Mercfarghen and Mchenry (2010) computer-assisted instruction is a programme of instructional material presented by means of a computer system. According to them (Benton, Cisholm,Tytler, Bell, Marcfarghen and Mchenry), in CAI, instructional computers are basically used in two ways, either they present a straightforward presentation of data or they fill a tutorial role in which the student is tested in comprehension. They (the authorities) explained that, if a computer has a tutorial programme, the student is asked a question by the computer; the student types in answer and then gets an immediate response to the answer. If the answer is correct, the student is routed to a more challenging problem; if the answer is incorrect, various computer messages will indicate the flaws in the procedure and the programme will bypass more complicated questions until the student shows mastery in that area. 
In CAI, according to the authorities, a computer programme can be used diagnostically, and once a student's problem has been identified, it can then focus on the problem area. The authorities indicated that, CAI provides one-to-one interaction with a student as well as an instantaneous response to the answers elicited and allows students to proceed at their own pace. They added that, because of the privacy and the individual attention afforded by the computer, some students are relieved of the embarrassment of giving an incorrect answer publicly or of going more slowly through lessons than others in the class.

Rendering more on the importance of computer-assisted instruction, Abimbade and Egunjobi (2003) stated that CAI presents information to the learner at his own pace. According to Abimbade and Egunjobi, the tutorial programme of the computer assumes that, the learner is in a 'tabula rasa' state. It presents some leaning materials and asks questions. It then compares the response with the expected answers. If the learner is unable to get the correct answer, it will then present to the learner some basic concepts that will represent the first frame all over again. The computer can repeat these processes as many times as required. In this way, the mastery of the subject matter is the concern of the computer-based instruction.

From the above passages, it is ostensible that, computer-assisted instruction is the presentation of instructional material through the use of the computer, and the sole aim is to enhance learning process. In trying to determine the effects of computer-assisted instruction on learning, different studies carried out in the past had focused majorly on the science subjects with nothing on government as a subject. It is against this backdrop that the researcher sought to investigate the effect that computer-assisted instruction would have on secondary school students' academic achievement in the learning of government as a subject. Specifically, the study sought to investigate the effect that computer-assisted instruction (CAI) used in collaboration with conventional instructional method (TIM) would have on secondary school students' academic achievement in the learning of government as a subject.

\section{Hypothesis}

The following hypothesis was tested at 0.05 level of significance in respect of the study.

There is no significant difference between the mean achievement scores of students taught government using the conventional instructional method (CIM) alone and the mean achievement scores of students taught government using computer-assisted instruction (CAI) at secondary school level.

\section{METHOD}

In the research, post-test only experimental design was employed with one experimental group (CAI model) and one control group (Conventional instruction method). 100 SS II government students from a private secondary school in the North Central geo-political zone of Nigeria were drawn using the purposive sampling technique. This was to ensure that, only students from the two arms of SS II that offered government participate in the study. The basis for the selection of the school include availability of at least 25 functional computers and a computer instructor as well as exposure of the students to computer in their junior secondary (JS I-III) and senior secondary (SS I) classes. In the secondary school that was used, there were two arms of SS II government class made up of 50 students each. 
The two classes were purposively selected to participate in the study with one class as experimental group and another as control group. The researcher-constructed instrument used in the investigation is called Government Achievement Test (GAT). The test (GAT) comprised 25 items which reflected the following main topics in SS II government syllabus: (i) civil service, (ii) public corporations and (iii) local government. The 25 items in the GAT contained 20 multiplechoice and 5 essay type items based on the topics treated. The GAT was validated by one expert in political science and one expert in measurement and evaluation.. Using the Pearson Product Moment Correlation Coefficient, the reliability coefficient of GAT was 0.86 which showed that, the instrument was reliable and appropriate for the study.

In line with the focus of the study, two teaching strategies were employed. They were: (i) computer-assisted instruction method (CAIM) and (ii) Conventional instruction method (CIM). In the case of the CIM, the normal procedure for lesson planning and delivery was applied. As for the CAIM, it was programmed in a Compact Disc Read Only Memory (CD ROM) by an expert in computer programming. It was the same experts that validated GAT that also validated CAIM and CIM. The study lasted for eight weeks.

Both the experimental and control groups were respectively exposed to CAIM and CIM. In the study, the experimental group was allocated to a computer on ratio of one student to a computer. At the end of the eighth week of the study, the GAT was administered on the students. In analyzing the data for the posttest, the t-test statistics was applied.

\section{RESULTS}

Table 1: t-test analysis of the effect of Computer Assisted Instruction on the achievement of students in Government as a subject

\begin{tabular}{|l|c|c|c|l|l|l|}
\hline Group & $\mathrm{N}$ & Mean & Std. Deviation & Df & t-cal & $\begin{array}{l}\text { Sig. ( 2- } \\
\text { tailed) }\end{array}$ \\
\hline $\begin{array}{l}\text { CAl } \\
\text { Group }\end{array}$ & 50 & 75.76 & 10.60 & & 10.287 & .000 \\
\hline $\begin{array}{l}\text { Control } \\
\text { Group }\end{array}$ & 50 & 58.32 & 5.58 & 98 & \\
\hline
\end{tabular}

Table 1 shows that, the students who were taught government using computer assisted instruction (CAI) had post-test mean achievement score of 75.76 with standard deviation of 10.60 while the students who were taught government using the conventional instruction method had posttest mean achievement score of 58.32 with standard deviation of 5.58. t-test analysis of the difference in the mean achievement scores of students taught government using CAI and those taught government using conventional instruction method revealed a t-calculated value of 10.287 with associated probability value of 0.000 . Since the probability value of 0.000 is less than the 0.05 level of significance, the null hypothesis was rejected.

Thus, there is a significant difference in the mean achievement scores of students taught government using CAI and those taught government using conventional instruction method. 


\section{DISCUSSION}

The findings of the study revealed that, there was significant difference in the mean achievement scores of students taught government using computer-assisted instruction (CAI) and those taught government using conventional instruction method (CIM). This implies that, students exposed to computer-assisted instruction significantly performed better in government than students exposed to conventional instruction method. The above superior academic achievement discovered in the study could be due to the fact that, the computer system of instruction has the ability to subject the learner to some drills until the concept involved or the subject matter is understood. This superior achievement due to the use of CAI is in consonance with the findings of Elman and Glen (1987) who found that, well designed and implemented computer-assisted instruction used as a supplement to traditional instruction (conventional instruction method) produced an educationally significant improvement in students final examination achievement.

\section{CONCLUSION}

Based on the findings of the study, it was concluded that, computer-assisted instruction used as a supplement to conventional instruction method enhances higher academic achievement in government as a subject among students. The study further revealed that, there was significant difference in the mean achievement scores of students taught government using computerassisted instruction and those taught government using conventional instruction method.

\section{Recommendations}

The study made the following recommendations.

- Government should not hesitate to fully introduce and implement computer-assisted instruction in secondary schools to enhance quality learning and teaching of government as a subject and all subjects.

- To ensure the sustainability of any planned CAI programme for secondary schools in Nigeria, government must ensure its (CAI programme) adequate and consistent funding.

- Professional bodies and private individuals should strive to complement government effort in providing necessary information and communication technology facilities to secondary schools.

- Government should massively train and retrain teachers on the use of internet, computer and other related digital tools for instructional purposes in all subject areas in secondary schools.

- School administrators should demonstrate interest in embracing and using information and communication technology facilities for computer-assisted instruction in all subject areas. 


\section{REFERENCES}

[1] Abimbade, A. \& Egunjobi, A. (2003). Effect of two computer-assisted instructional modes on secondary school students' achievement in practical geography in Ibadan metropolis, Nigeria. Nigeria Journal of Computer Literacy. Vol. 4 (1), 102-112.

[2] Benton, W., Chisolm, H., Tytler, J., Marchfarguher,. M. \& Mchenry (2010). Computer-assisted instruction. Retrieved 30th November, 2016 from http://www.britanica.com/editor/-Editors-ofEncyclopaedia-Britanica/4419

[3] Duze, C.O. (2011). Falling standard of education in Nigeria: an empirical evidence in Niger Delta. Journal of Contemporary Research. Vol. 8 (3).

[4] Elman, L. \& Glen, A. (1987). Computer-based education in social studies. Bloomington. New Indiana University.

[5] Jones, J. C. (2017). Computer-assisted instruction. Retrieved on 29th November, 2016 from http://www.newworldencyclopaedia.org.entry.

[6] Olugbenga, O. (2016). Falling standard of education in Nigeria: the causes and permanent solutions. Retrieved on 18 December, 2016 from http://www.google.com/amps/gbengaogun.com/2016/06/27/falling - standard -of - education-innigeria-the-causes-and-permanent-solutions/amps/

[7] Rogers, P. L., Berg, G. A., Boettcher, J.V., Howard, C., Justice, 1. \& Schenk, K.D.(1995). Computer assisted instruction. Retrieved on 5th March 2017 from http://www.g.global.com/book/encyclopaedia - distance - learning-second edition /352

[8] Uwameiye, R. (2014). Falling standard of education in Nigeria: causes and solutions. Studies in Education. Vol. 14 (1).

[9] WikiEducator (2008). Computer-assisted instruction. Retrieved on 7th February, 2017 http://www.wikieducator.org.computer?_assisted_l... 